\title{
Faculty and Student Perceptions of Strategies for Effective Student Engagement in the Performing Arts Before and During COVID-19
}

\author{
James Hutson \\ Lindenwood University \\ Katherine Herrell \\ Lindenwood University
}

The efficacy of various modalities to engage students and learning outcomes has been debated, but not yet studied, even though the relationship between student engagement and performance is well-documented. Studies have shown how perceived levels of engagement among students lead to greater persistence and completion rates across diverse populations. This study investigates the relationship between the perceived engagement of both students and faculty in different modalities from Fall 2019-Fall 2020 in the performing arts before and during the pandemic. The study confirms that there was a lower perceived level of engagement in the Spring of 2020 as faculty did not have time to prepare to move activities online. However, students were, in fact, more engaged than faculty believed in all terms and valued feedback and engaging with faculty and other students, while faculty valued students being face-to-face and/or synchronous virtually. Faculty noted how important independent practice was, such as recording/submitting work and rehearsing outside of class. Students, on the other hand, desire guided practice.

Keywords: COVID-19, engagement, performing arts, hybrid

\section{INTRODUCTION}

Student engagement has been demonstrated to have a positive effect on academic performance and student retention (Chapman, 2002-2003; Coates, 2005; Kuh, Cruce, Shoup, Kinzie, \& Gonyea, 2008; Pascarella, Seifert, \& Blaich, 2010). Engagement in the form of educationally effective practices can take place both in and out of the classroom and lead to many different measurable outcomes. Kuh, Kinzie, Buckley, Bridges, and Hayek (2007) define student engagement as being represented by two features. The first is the amount of time and effort that students put into their studies, while the second is what the institution does to support student learning, including deploying resources, curriculum, support services, and other activities. In essence, the features of student engagement are two sides of the same coin in that student effort, persistence, and success in coursework is directly affected by institutional strategies. One of these considerations is modality and adapting to new and changing circumstances. The difference between engagement in online versus traditional face-to-face courses has been well-studied (Ahlfeldt, Mehta, \& Sellnow, 2005; Lindblom-Ylänne, Trigwell, Nevgi, \& Ashwin, 2006; Günüç \& Kuzu, 2014; Montgomery, Hayward, Dunn, Carbonaro, \& Amrhein, 2015). Studies conclude that engagement is certainly possible in any modality, but strategies differ between synchronous and asynchronous classroom activities. The 2020 
pandemic was highly disruptive for traditional face-to-face teaching, and instructors had to pivot very quickly to begin engaging with students outside of the classroom. The new flipped model that many institutions adopted has yielded early results on student engagement to which this study will also contribute (Singh, 2021).

In order to safely reopen in Fall 2020, universities considered many approaches, including delaying the start of the term, moving classes entirely online, and even not holding classes again until Spring 2021 (Renton, 2020). In the end, two of the most popular modalities adopted were the HyFlex and blended classroom models, which allowed students to attend in class and observe social distancing, while others could join synchronously through video conference. At the same time, the lectures were recorded for those that could not join to be made available for viewer at a later date (Kyei-Blankson \& Godwyll, 2010). While HyFlex course design is not new for higher education, the effectiveness of learning outcomes and student engagement has not been thoroughly studied in the current climate. HyFlex and blended learning strategies require more of students outside of the classroom with regards to learning activities and assessments (Cabi, 2018). As such, lessons learned from the first year of the pandemic illustrate the need to approach blended learning with purpose. Studies confirm that work and activities assigned outside of the classroom fail to engage students unless tied to an incentive, such as a significant percentage of the final grading scheme (Singh, 2021). However, a thorough study of the kinds of activities that students and faculty perceive to be most engaging has, as of yet, not been conducted.

This study seeks to investigate the perceived level of engagement from both student and faculty perspectives relating to modality pre- and mid-pandemic, as well as identify the types of activities both parties found to be the most engaging. The study surveyed the nature of perceptions of engagement across time and in different modalities from both student and faculty perspectives in the Performing Arts from Fall 2019, where most classes were delivered in a face-to-face manner before the pandemic; Spring 2020, where all classes went virtual after Spring Break in March with little warning or preparation possible; and Fall 2020, where classes were held in a hybrid format, limiting class size, and utilized live streaming classes through the University LMS and recorded lectures for viewing later. The results of the survey were compiled and then compared to aggregate institutional data associated with retention rates from Fall 2019 to Spring 2020 and Fall 2020 to Spring 2021.

The survey tool used sought to gather demographic information, identify perceived engagement by term, and, finally, identify the types of activities that were seen to be the most effective relating to engagement from the perspective of both students and faculty. Demographic information was collected from students in the three areas of the Division of Performing Arts: Music, Dance, and Theatre. Next, perceived engagement was assessed via a Likert scale for the three terms in question. Students were asked to identify if they were taking primarily major courses, general education courses, or a mixture of both. It is important to note that the major courses were in studio format instead of lecture; students work collaboratively on performances instead of primarily watching lectures, reading, or conducting traditional research. Students were then asked to rank the activities that they found to be the most successful and led to a high level of engagement over the terms considering the limitations of the pandemic. The survey concluded with two open-ended questions to assist in identifying any additional activities that the students found to be most and least engaging regarding instructors and/or courses. Faculty in the division were given the same survey, though the additional demographic indicators were removed. The perceived engagement of students across their classes for the three terms was also ranked via a Likert scale, and the perceived most and least engaging class activities/approaches were queried.

The results of the study confirm the assertion of Learning Reconsidered in that learning and engagement rely on the dual areas of student knowledge of classroom activities and participation in co-curricular activities (ACPA \& NASPA, 2004). The study confirms that there was a lower perceived level of engagement in the Spring of 2020 as faculty did not have time to prepare to move activities online. However, students were, in fact, more engaged than faculty believed in all terms. At the same time, the activities perceived to be the most effective for high levels of engagement were mismatched between students and faculty. Students valued feedback and engaging with faculty and other students, while faculty valued students being face-to-face and/or synchronous virtually. Faculty noted how important independent 
practice was, such as recording/submitting work and rehearsing outside of class. Students, on the other hand, desire guided practice. The activities that students found to be most engaging outside of class related to working with groups and engaging with one another and/or the instructor. There was a strong dislike for perceived "busywork," or assignments that students felt did not positively contribute to their learning in a meaningful way. What is clear from the study is that the students could engage outside of the classroom and the model is effective, however, certain strategies must be adopted in order to ensure a continued positive correlation between course design, activities, and engagement. Through the building of community and bridging in-class and co-curricular activities, high levels of engagement can be maintained even in a pandemic in a field that often necessitates face-to-face collaboration between students and faculty. The recommendations of the study may be applied to all disciplines for consideration.

\section{LITERATURE REVIEW}

The influence student engagement has on student success and learning outcomes in higher education has been thoroughly researched and demonstrated. In fact, as Trowler and Trowler (2010, p.1) relate, "the value of engagement is no longer questioned." Broadly speaking, the literature approaches student engagement as the "interaction between the time, effort and other relevant resources invested by both students and their institutions intended to optimise the student experience and enhance the learning outcomes and development of students and the performance, and reputation of the institution" (Trowler \& Trowler, 2010, p.2). Institutions now focus heavily on how well they are doing with student engagement due to the clear association between engagement and other variables, including student retention and academic performance (Chapman, 2002-2003; Coates, 2005; Kuh et al., 2008; Pascarella et al., 2010; Harper and Quaye, 2015). However, while the importance of engagement is seemingly no longer questioned, as the assessment of outcomes is often directly tied to the notion of the quality in education, the term "engagement" itself is complex (Mandernach, 2015). For instance, there is debate over the construct in that there needs to be a distinction between the nature of the engagement, as well as its precedents and results (Kahu, 2013); as well, Fredricks, Blumenfeld, and Paris (2004) have further divided engagement into three types: behavioral, emotional, and cognitive. Finally, there has been little research on the distinction between types of engagement by field, especially that of the arts (Leach, 2016). With regards to the best practices for student engagement in the hybrid or distance education modalities higher education finds itself in currently, lessons can be learned from the performing arts (e.g. Music, Dance, and Theatre), who historically have a higher level of reported student engagement than other fields. Specifically, the major areas of consideration are: the role of technology to support student learning, engaging activities appropriate to different modalities, discipline-specific approaches to student-teacher interactions, and students' ownership of their own education.

There have been many ways researchers have approached student engagement. Kahu (2013) has outlined the four principal research approaches on student engagement. The first is the behavioral perspective that is most concerned with the behavior of students as related to institutional practices. The second is the psychological perspective that defines engagement more as an individualized psycho-social process. The third is the socio-cultural perspective that points to the role played by socio-political context in engagement. Finally, the fourth is the holistic perspective that takes the broadest view of engagement. As a result of the disconnected nature of these various perspectives, following the approach of Zepke (2011), Kahu (2013) proposes a new conceptual framework with complexity theory as a way to understand how engagement is not static, but a "dynamic and non-hierarchical network" of interconnected factors (2013, p.758). For instance, we would consider institutional practices as merely one facet that contributes to the socio-cultural and psycho-social processes in which students and faculty perceive engagement in broad terms.

Kahu (2013) also highlights the problematic nature of student engagement pointing out that the underlying assumptions and notions have been "weakly theorised" (p.759) .Most studies tend to focus on the role the institution, instructor, or technology play in engagement (Ahlfeldt, Mehta, \& Sellnow, 2005; Barkley, 2010; Fredricks, 2013). Kahu instead argues that the student contribution must not be overlooked, 
as in the psycho-social process noted by Kahu (2013). Through realist social theory, the study looks at how student engagement can be seen to be related to the acceptance of responsibility of one's own education in the face of uncertainty. More specifically, Kahu argues that student engagement is related to extended, restricted, and even fractured modes of reflexivity and co-reflexivity. Pascarella and Terenzini (2005) echo the belief when stating: "The impact of college is largely determined by individual effort and involvement in the academic, interpersonal, and extracurricular offerings on a campus" (p. 602). Matthews (2016) supports the model by arguing for collaborative learning partnerships to foster greater engagement. Through this approach learning activities labeled as "high impact" lead to greater student engagement and better learning outcomes because of distributed agency whereby the learning environment impacts the agency mediated by reflexivity. In other words, the social relations that develop from the psycho-social and sociocultural processes ensure that the more responsibility a student takes for their own role in the learning environment, the higher the engagement and more successful the learning outcomes. The results are especially relevant for the study at hand and the population of students that are already highly invested in their learning and engaging reflexively.

The studies outlined above have certainly noted the complexity of student engagement and warn against lumping students into one homogenous group that seem to all be experiencing the same internal and external factors. The National Survey of Student Engagement (NSSE), for instance, is increasingly used in countries around the world to make comparisons across disciplines relating to student engagement. Yet, there has been little attention paid to the variance and distinctions between disciplines relating to engagement. Leach (2016) argues that teaching varies greatly across disciplines and that has a direct impact on the results on studies such as the NSSE relating to engagement. For instance, Neumann, Parry, and Becher (2002) have identified differences in the classification of disciplines of "hard/soft" and "pure/applied" to demonstrate differences in pedagogy, curriculum, teaching methods, assessment and more. Lindblom-Ylänne, Trigwell, Nevgi, and Ashwin (2006) support the assertion in noting that academics from the so-called "hard" disciplines, like the physical sciences, more commonly used teacher-centric approaches to content delivery, whereas those from "soft" disciplines, like the social sciences, used more student-focused approaches. Leach's study included ten fields of study: natural and physical sciences, information technology, engineering and related technologies, architecture and building, agriculture and environmental studies, health, education, management and commerce, society and culture, and creative arts. A comparison of the areas makes the divergent approaches mentioned above clear with the creative arts faring far better than the other areas on student-staff interactions (mean difference $=6.619, \mathrm{p}=0.000$ ). Additionally, the creative arts also reported being the most engaged with all six criteria showing positive differences from all other fields. On the other hand, management, as well as society and culture, were both less actively engaged with both reporting six negative differences. Clearly, discipline-specific approaches have a demonstrable effect on the criteria for engagement as outlined in surveys such as the NSSE on all six student engagement scales. As such, Leach argues for such data to either only be used within a given area and not compared between disciplines or to adopt a more holistic definition of engagement.

Fuller (2014) outlines a discipline-specific approach for student engagement in a study of first-year orientation courses. Fuller, who is a professor of theatre history, developed and then offered "Arthur Miller and Social Drama" in Fall of 2012 to address the needs specific of first year theatre majors at Rider University. The learning activities included viewing and discussing two films, reading, then discussing ten essays and five plays, and, finally, attending the department's production of The Crucible. Students also presented papers on a play that was not assigned as part of the class at a symposium at the end of the term. As with other first-year seminars, time was set aside to address the culture of the institution, academic advising, and time management strategies. Evaluations indicated an overwhelmingly positive response from students, which was confirmed by an $100 \%$ retention rate for the pilot class. The efficacy of such offerings that align engagement with a particular population and their interests need be considered.

Studies like that of Leach (2016) and Fuller (2014) make clear the different disciplinary approaches to teaching and learning have an impact on student engagement. Furthermore, the creative arts have a higher level of faculty/staff-student interactions and more student-centered teaching, which leads to better student engagement. But despite this and the abundance of studies on student engagement, little attention has been 
paid to the strategies employed in the arts, especially the performing arts. The few studies that do exist focus primarily on how the arts in general can be leveraged across the curriculum to improve engagement. For instance, Garrett (2013) outlines a program at Oklahoma City University that uses a faculty learning community approach. The arts across the curriculum program focused on offering specific, innovative courses that promoted creative problem solving through aesthetic engagement. Taught in an interdisciplinary cohort, classes produced artworks instead of research papers to contextualize their findings. The students surveyed confirmed that $97 \%$ would indeed be interested in enrolling in another artsintegrated course. NSSE results for first-year students and seniors from 2006 to 2010 reported that they attended a significantly higher average of art exhibits, plays, dance recitals, concerts, or other performances than the national average (Garrett, 2013).

The faculty learning community model is but one that has been devised to improve student engagement, but is difficult to scale without special resources and funding, as with the OCU example, and is centered on small learning communities in a face-to-face modality to foster close collaboration between students and teachers. How might the engagement seen in the arts be supported through technology and leveraged for hybrid or HyFlex learning? The role technology plays in student engagement has re-emerged as a primary area of interest as institutions across the country shift to distance education and virtual learning. Günüç and Kuzu conducted such a study in 2014 to determine the effect of students views on technology relating to engagement. The grounded theory study confirmed that while class and campus engagement were indeed significant factors, the integration of technology was not necessary for student engagement. However, even though technology was not necessary to have high levels of engagement, effectively integrating it into a course was found to contribute to higher levels of student engagement. In fact, the use of technology in various instructional activities was seen to have a positive corollary for student engagement. The goal of the study was to demonstrate the need to integrate more technology into the classroom for instructors who were not digital natives like their students. Most college professors would instead be considered digital immigrants (Bayne \& Ross, 2007). The previous study focused on pre-pandemic expectations and conditions in higher education and on enhancing a face-to-face experience, and not hybrid, HyFlex, blended, asynchronous, or online learning.

The importance of building learning communities and feedback on student engagement is even more critical for online, asynchronous and distance education experiences. As noted by Darby (2019), "Engagement doesn't happen as naturally in online classes as it does in person" (p. 88). As engagement is often disconnected from face-to-face activities, multiple opportunities for engagement and feedback need to be built into online experiences. In addition to scaffolding larger tasks, providing frequent feedback is necessary to ensure effective student learning and to create the sense of a learning community. Given how easy it is for online students to feel isolated or disconnected, regular opportunities for engagement and instructor or peer feedback meets the learning styles of a diverse population that often needs a guided learning experience. In approaching feedback, Darby recommends the dual considerations of both time and effectiveness. Instead of taking an extended time to grade one summative assignment, feedback needs to come frequently through mini-assignments over regular intervals in the term and have a shorter turnaround time to ensure the recommendations provided can be effectively applied to the next task in the scaffolded assignment. How instructors leverage technology is critical in the online learning environment.

The role technology plays in student engagement for blended learning was conducted by Montgomery, et al. (2015) and supports the results seen above for this new modality. In the three-year study that explored the challenges of integrating digital technology in blended learning classes, the role of digital innovation in support of diverse learners, and how to build meaningful connections with technology, found that careful considerations result in higher engagement. For instance, if instructors considered the four key areas, then blended learning was found to be effective in ensuring learners shifted to being more active agents in their learning, thus supporting the findings of Kahu (2013). The combination of face-to-face student-centered learning with digital technologies supported through a Learning Management System (LMS) to produce a virtual space for learning and experimentation resulted in better student outcomes, as well as reported engagement. The four specific areas identified by the team are: designing digital resources, scaffolding student learning, learner customization, and promoting the lived experience. The considerations outlined 
align with several of the five types of interactive engagement for blended learning, which include studentto-student, student-to-teacher, student-to-community, student-to-technology, and student-to-material (Prohorets \& Plekhanova, 2015). While the study focused on implementation and the scaling of education in new modalities, such as Massive Open Online Courses (MOOCs), this approach aligns with the approach implemented at Lindenwood University in response to the pandemic.

Finally, the role of feedback in considerations of student engagement is critical, especially with the model under review here. As noted, student engagement has two features that include both the effort dedicated by the students themselves and the support provided by the institution (Kuh, Kinzie, Buckley, Bridges \& Hayek, 2007). Feedback would fall under the latter category and is critical for student engagement. Hattie (2012) argues that in order to create an optimal classroom environment for learning and to make "learning visible," regular and meaningful feedback must accompany any assignment and assessment (p.1). The ability of educators to adapt to different learning styles and contexts relies, not only on providing meaningful feedback to students, but also on observing and gathering data on the impact their teaching style has on different individuals. Especially in the new blended learning model, lessons rarely go as planned each class time and the ability to pivot ensures that progress towards learning goals may be met. Taking note of areas where there is confusion with the material and which students may be falling behind will allow approaches to be modified in the interim between class meeting times to ensure all students can meet the learning criteria.

Studies have demonstrated a positive correlation between student engagement and success, as well as better learning outcomes in higher education. Institutions focus on how well they are doing with student engagement due to the clear association between engagement and other variables, including student retention and academic performance (Chapman, 2002-2003; Coates, 2005; Kuh et al., 2008; Pascarella et al., 2010). With regards to best practices for student engagement in the hybrid or distance education modalities, lessons can be learned from the performing arts, which historically have a higher level of reported student engagement than other fields. Specifically, the major areas of consideration are: the role of technology to support student learning, engaging activities appropriate to different modalities, disciplinespecific approaches to student-teacher interactions, and student ownership of their own education. Most studies tend to focus on the role the institution, instructor, or technology play in engagement (Ahlfeldt, Mehta, \& Sellnow, 2005; Barkley, 2010; Fredricks, 2013). Kahu (2013) reminds that the student contribution must not be overlooked, particularly the psycho-social process. The student-centric model here aligns with the learning community and discipline-specific approaches taken at institutions relating to the arts that have yielded positive results (Garrett, 2013; Fuller, 2014; Leach, 2016). Finally, ensuring that the type of learning activities align with the specific modality, and how those need to be tailored utilizing regular feedback point to the need of further study into the viability of approaches as seen over the course of the first year of the pandemic (Kuh, Kinzie, Buckley, Bridges and Hayek, 2007; Hattie, 2012; Montgomery, et al., 2015).

\section{METHODOLOGY}

In this mixed-methods study we collected data from students and faculty, as well as aggregate institutional data from Lindenwood University, a private, four-year, liberal arts institution in the suburban ring of St. Louis, Missouri. We distributed a Qualtrics survey via the University learning management system (Canvas) to all 224 performing arts majors, which included 45 students from Dance, 76 students from Music, and 103 students from Theatre. Of the 43 student respondents, there were 7 First-Year students, 15 Sophomores, 10 Juniors, and 11 Seniors. They represented all three departments within the performing arts: Dance (9), Music (2), and Theatre (21). Twenty-five percent of the students identified as FirstGeneration college students, $96 \%$ identified their race as White, and $79 \%$ identified as Female. At the same time, we distributed a separate Qualtrics survey via the University learning management system to all 11 full time faculty ( 2 from Dance, 4 from Music, and 5 from Theatre) and all 27 adjunct instructors (4 from Dance, 20 from Music, and 3 from Theatre) in the Performing Arts. Six full time faculty and 4 adjunct 
instructors ( 3 from Dance, 2 from Music, and 5 from Theatre) responded to the survey. Sixty percent of the faculty/instructors were Female and $40 \%$ were Male.

We distributed the survey at the end of the Fall 2020 semester, and we asked the participants to consider the previous three semesters: Fall 2019 which was entirely face-to-face in the classroom, Spring 2020 when there was an abrupt pivot to virtual learning mid-semester, and Fall 2020 when the course offerings were flexible with some attendance face-to-face and some online. We asked the participants to indicate via a 110 Likert scale their perceptions of student engagement in each of the three scenarios described above. We asked the students to indicate if they were primarily taking major courses, general education courses, or a mix of major and general education courses for each of the semesters that they were rating. Then we provided a list of engagement activities (discussions outside of class, rehearsals outside of class, collaborating with other students outside of class, group work outside of class, group work inside of class, virtual conferencing one-on-one with the instructor, instructor feedback on individual/group assignments, peer review/ critique, live virtual lectures, live virtual rehearsals, discussions inside class, self-evaluation, watching performances/demonstrations of technique, and recording and submitting monologues/ performances/ rehearsals), and asked the participants to rank them in order of most to least effective in leading to high levels of student engagement, while considering the limitations of the pandemic. We drew the engagement activities from previous literature (Barkley, 2010; Fredricks, 2013; Cabi, 2018), along with discipline-specific alternatives for the performing arts (Hensley, 2005; Pulham, 2018). We had presented the potential in-class and out-of-class activities in training which we made available to all performing arts faculty within the school in preparation for the Fall 2020 term. Finally, we posed open-ended questions to all participants. We asked students to list the activities that they found most engaging within a class and which activities they found least engaging. Similarly, we asked faculty to list which activities they found to result in the most engagement with students and which activities they found to result in the least engagement with students.

\section{RESULTS}

In considering the definitions of engagement outlined above, this study frames engagement in the conceptual framework that seeks to understand the role modality played in engagement from pre- to midpandemic (Fall 2019-Fall 2020). We invited performing arts students and faculty to participate in a survey that asked them about their perceptions of the levels of student engagement in this period. We asked them to rank from 1-10 the overall levels of student engagement during each semester of the time period, and we asked students to report in which types of courses (major, general education, or a mix of both) they were enrolled in during each of the three semesters. We asked all participants to rank in order of most to least effective types of classroom instructional strategies and were asked in open-ended questions which strategies they perceived as either the most or least engaging.

During the pre-pandemic Fall 2019 semester, students perceived the mean of engagement was 8.35 with a standard deviation of 3.98 and a variance of 4.6. Similarly, the faculty/instructors perceived student engagement to be at a mean of 8.3 with a smaller standard deviation of 1.00 and smaller variance of 1.01 . $55 \%$ of the students reported that they took a mix of major and general education classes that semester, $45 \%$ of students reported that they took mostly major classes, and 5\% of students reported that they took mostly general education classes.

For the disrupted Spring 2020 semester, students reported a mean score of perceived of 5.37 out of 10 on the Likert scale with a standard deviation of 2.15 and a variance of 4.60 . Faculty/instructors reported their perception of student engagement to be higher at a mean of 6.30 with a standard deviation of 2.05 and a variance of 4.21 . Thirty-nine percent of students reported that they took a mix of major and general education classes that semester, 52\% reported taking mostly major classes, and almost $8 \%$ reported taking mostly general education courses.

For the Fall 2020 semester, for which we planned in advance for HyFlex instruction, the students' scoring relative to their own engagement via the Likert scale was 5.95 with a standard deviation of 2.36 and a variance of 5.56. Faculty perceived slightly lower student engagement with a mean of 5.67 with a 
standard deviation of 3.20 and a variance of 10.22. Seventy-one percent of students reported taking mostly major classes during the Fall 2020 semester, while almost 24\% reported taking a mix of major and general education classes. Only $4.76 \%$ of students reported taking mostly general education courses.

Participants ranked in order of the most to least effective in leading to higher levels of student engagement the following list of teaching strategies: discussions outside of class, rehearsals outside of class, collaborating with other students outside of class, group work outside of class, group work inside of class, virtual conferencing one-on-one with the instructor, instructor feedback on individual/group assignments, peer review/critique, live virtual lectures, live virtual rehearsals, discussions inside class, self-evaluation, watching performances/demonstrations of technique, and recording and submitting monologues/ performances/rehearsals. These mean rankings are displayed in Table 1 below. The students indicated that the five most engaging techniques were virtual conferences one-on-one with the instructor (mean rank of 7.03), in class discussions (mean rank of 7.00), instructor feedback on individual or group assignments (mean rank of 6.47), live virtual rehearsals (mean rank of 6.21), and peer review/critique (mean rank of 6.09). The faculty/instructors indicated that the five most engaging techniques were live virtual rehearsals (mean rank of 9.00), virtual conference one-on-one with instructor (mean rank of 7.90), watch performances/demonstrations of technique (mean rank of 7.71), rehearsing outside of class (mean rank of 7.50), and recording and submitting monologues/performances/rehearsals (mean rank of 7.40). Students indicated that the least engaging techniques were group work outside of class (mean rank of 4.03), collaborating with other students outside of class (mean rank of 4.91), discussions outside of class (mean rank of 4.99), self-evaluation (mean rank of 5.32), and groupwork inside of class (mean rank of 5.34). Faculty indicated that the least engaging techniques were groupwork outside of class (mean rank of 4.33), discussions outside of class (mean rank of 4.33), collaborating with other students outside of class (mean rank of 6.00), live virtual lectures (mean rank of 6.17), and self-evaluation (mean rank of 6.50).

TABLE 1

\section{MEAN RANKINGS OF ENGAGEMENT TECHNIQUES}

\begin{tabular}{|l|l|l|}
\hline Technique & $\begin{array}{l}\text { Students } \\
\mathrm{n}=43\end{array}$ & $\begin{array}{l}\text { Faculty } \\
\mathrm{n}=10\end{array}$ \\
\hline Virtual conference one-on-one with instructor & 7.03 & 7.90 \\
\hline Discussions inside class & 7.00 & 7.30 \\
\hline Instructor feedback on individual or group assignments & 6.47 & 7.00 \\
\hline Live virtual rehearsals & 6.21 & 9.00 \\
\hline Peer review/critique & 6.09 & 6.67 \\
\hline Watch performances/demonstrations of technique & 6.05 & 7.71 \\
\hline Live virtual lectures & 5.90 & 6.17 \\
\hline Record and submit work & 5.71 & 7.40 \\
\hline Rehearsing outside of class & 5.64 & 7.50 \\
\hline Groupwork inside of class & 5.34 & 7.00 \\
\hline Self-evaluation & 5.32 & 6.50 \\
\hline Discussions outside of class & 4.99 & 4.33 \\
\hline Collaborating with other students outside of class & 4.91 & 6.00 \\
\hline Groupwork outside of class & 4.03 & 4.33 \\
\hline Other & 0.75 & 0.00 \\
\hline
\end{tabular}

For the open-ended questions about which specific activities students found most engaging, at least $28 \%$ of the students mentioned discussions with a clear preference for synchronous discussions, and $11.6 \%$ preferred in-person classes. Small group work, games/challenges/special projects, and instructor feedback/one-on-one time with instructors were mentioned at least three times each. Students overwhelmingly stated that watching videos and long lectures were the least engaging $(30 \%)$ and expressed 
frustration with times they either could not hear or see the instructor. Nineteen percent of the student respondents mentioned "busywork," such as note taking and some group work, as not engaging, and at least three students expressed a dislike of asynchronous discussions.

The faculty responses to which activities they found most and least engaging showed a clear preference for in-person instruction, discussion, and group work (60\%). One respondent indicated having success with keeping students engaged by having multiple due dates throughout the week, and another cited peer teaching as another helpful engagement strategy. Faculty also indicated frustration with not being able to see students either due to technology limitations or students choosing to have cameras turned off. Faculty commitment also seemed to be less strong than anticipated even though there was more time to prepare and additional training. There was a noticeable improvement from Spring 2020 to Fall 2020 with regards to perceived engagement among students, but the free responses revealed the frustrations of faculty with regards to asynchronous activities or the inability to accurately review student performance and provide feedback.

\section{DISCUSSION}

We learned from the survey data that students and faculty found similar activities to be important for high levels of engagement. However, there were also discrepancies in perspectives between students and faculty. What was consistent was the belief that engagement improved with time to prepare for a modality that included distance learning and more out-of-class activities. In Fall 2020, the mean of engagement was higher at almost $6 \%$. The top three activities that students ranked as most engaging were 1) virtual conferences one-on-one discussions with instructor, 2) in-class discussions, then 3) instructor feedback on individual or group assignments. The open-ended questions also provided insight into the student experience which showed in their consistent dislike of watching lectures passively and taking notes without engaging with the class or instructor. It is worth noting that the types of classes students took changed over the three terms and may have affected the results of their perceived engagement. For instance, from Fall 2019 to Spring 2020, students took a relatively balanced schedule of major and general education classes. In Fall 2019, 45\% of students took mostly major classes and 52\% did so in Spring 2020. Fall 2020 found $71 \%$ of students taking mostly major classes. It is possible that students gravitated towards major classes for the Fall of 2020 because studio-format classes would be in-person, which they were not in the Spring of 2020. Because of students gravitating towards in-person classes, and faculty responses confirming a preference for synchronicity, the evidence shows that those in the performing arts in this study prefer faceto-face classes.

There was a similar desire for synchronous activities and engagement among faculty surveyed. The faculty survey was taken by four adjuncts and six full-time faculty; only one full-time faculty member in the Music department answered the survey; no full-time Theatre faculty answered survey; and, finally, there was good representation among the Dance faculty with $100 \%$ of full-time faculty responding. With regards to the level of perceived engagement in classes, faculty ranked the Fall 2019 semester at 8.3, with little to no variance or standard deviation; Spring 2020 decreased to 6.3; and Fall 2020 decreased further to 5.6. The activities that faculty ranked as their top three most engaging were 1) live virtual rehearsals, 2) virtual conference one-on-one with instructor, and 3) watch performances/demonstrations of technique. As noted, while there was some overlap between students and faculty in their top five ranking, perceptions of which activities were most effective were somewhat mismatched. The repeated note of students disliking being disconnected from the instructor was reflected in the desire to have more direct feedback and contact. At the same time, another area of agreement between students and faculty was in the ranking of the least engaging activities. Both groups ranked group work/collaborating with other students outside of class, discussions outside of class, and self-evaluation in the bottom five. This feedback may indicate a need for more training on how to effectively facilitate asynchronous discussions, how to construct engaging cooperative learning experiences, and how to leverage student self-evaluation to increase engagement and learning. 
Consistent with Hattie's (2012) observations that feedback is important to student learning, the survey results demonstrate that students valued activities that involved feedback either by their instructors or peers. Faculty perceived engagement to be lower than students between Spring 2020 and Fall 2020, but perceived similar activities to be important for engagement. The alignment of students and faculty activities among the top five most engaging techniques included live virtual rehearsals and virtual conferences one-on-one with the instructor. While student and faculty rankings of the engagement techniques were aligned in some regard, it is noteworthy that students ranked three activities in their top five which faculty did not perceive to be among their highest-ranking activities for engagement. These activities included in-class discussions, instructor feedback, and peer-review/critique. These three choices indicate that students value activities that provide them with feedback. Notably, watching performances/demonstrations of technique, rehearsing outside of class, and recording and submitting work were ranked high by faculty, but not by students. Moreover, what these three have in common are that they do not involve interaction with nor feedback from the faculty, which is highly desirable for this population.

\section{CONCLUSION}

The effects of the global pandemic on higher education have included an adoption of more flexible modalities to ensure courses could be offered safely. The efficacy of these modalities is only now being studied, and understanding how to best engage students in new ways provides a model for other fields to follow. For the performing arts, working collaboratively in teams, both inside and outside of classrooms to prepare for performances, leads to greater perceived engagement from both the student and faculty perspectives. The study here confirms that there was a lower perceived level of engagement in the Spring of 2020 as faculty did not have time to prepare to move activities online. However, students were, in fact, more engaged than faculty believed. At the same time, the activities perceived to be the most effective for high levels of engagement were mismatched between students and faculty. Students valued feedback and engaging with faculty and other students, while faculty valued students being face-to-face and/or synchronous virtually. Faculty noted how important independent practice was, such as recording/submitting work and rehearsing outside of class. Students, on the other hand, desire guided practice. Both groups viewed discussions and group work outside of class and student self-evaluation as the least engaging activities. Interestingly, the activities identified by faculty freed up time in class for more engaging activities by making students more prepared outside of class. It appears that faculty valued quality preparation in that their top-ranked choices were live virtual rehearsals, virtual conferences one-on-one, and watching performances/demonstrations of technique. The mean rank of live virtual rehearsals was 9.00 among faculty, which indicates that although faculty preferred in-person instruction/rehearsals, they did see the live virtual rehearsals as the preferred substitute for the performance-based classes. We recommend further study into why faculty valued these activities over direct engagement and providing feedback for which students indicated a preference. Additionally, we recommend more faculty development relating to connecting with students, giving meaningful feedback, developing engaging cooperative learning experiences, and being present in a virtual environment. Through such training, the gap may be closed on effective teaching techniques as perceived by faculty and student satisfaction leading to further persistence by both parties. 


\section{REFERENCES}

American College Personnel Association (ACPA) \& National Association of Student Personnel Administrators (NASPA). (2004). Learning reconsidered: A campus-wide focus on the student experience. Washington DC: Authors.

Ahlfeldt, S., Mehta, S., \& Sellnow, T. (2005). Measurement and analysis of student engagement in university classes where varying levels of PBL methods of instruction are in use. Higher Education Research \& Development, 24(1), 5-20.

Barkley, E.F. (2010). Student Engagement Techniques: A handbook for college faculty. San Francisco, CA: Jossey-Bass.

Bayne, S., \& Ross, J. (2007). The 'digital native' and 'digital immigrant': A dangerous opposition. In Annual Conference of the Society for Research into Higher Education (SRHE). Brighton, Sussex, UK.

Cabi, E. (2018). The impact of the flipped classroom model on students' academic achievement. International Review of Research in Open and Distributed Learning, 19(3), 203-221.

Chapman, E. (2002-2003). Alternative approaches to assessing student engagement rates. Practical Assessment, Research, and Evaluation, 8(13), 1-7.

Coates, H. (2005). The value of student engagement for higher education quality assurance. Quality in Higher Education, 11(1), 25-36.

Darby, F. (2019). Small Teaching Online: Applying learning science in online classes. San Francisco, CA: Jossey-Bass.

Fredricks, J.A. (2013). The measurement of student engagement: A comparative analysis of various methods and student self-report instruments. In S.L. Christenson, Handbook of Research on Student Engagement (pp. 763-782). New York, NY: Springer.

Fredricks, J.A., Blumenfeld, P., \& Paris, A. (2004). School engagement: Potential of the concept, state of the evidence. Review of Educational Research, 74, 59-109.

Fuller, I. (2014). Redesigning the first-year orientation course: How a discipline-specific approach can deepen student engagement. Liberal Education, 100(3). Retrieved from https://www.aacu.org/publications-research/periodicals/redesigning-first-year-orientation-course

Garrett, C. (2013, May-June). Promoting student engagement and creativity by infusing art across the curriculum: The arts integration initiative at Oklahoma City University. About Campus, pp. 2732.

Günüç, S., \& Kuzu, A. (2014). Factors influencing student engagement and the role of technology in student engagement in higher education: Campus-class-technology theory. Turkish Online Journal of Qualitative Inquiry, 5(4), 86-113.

Harper, S., \& Quaye, S.J. (2015). Making Engagement Equitable for Students in U.S. Higher Education. In S. Harper \& S.J. Quaey (Eds.), Student Engagement in Higher Education: Theoretical Perspectives and Practical Approaches for Diverse Populations. New York \& London: Routledge.

Hattie, J. (2012). Visible learning for teachers: Maximizing impact on learning. New York \& London: Routledge.

Hensley, G. (2005). Creating a hybrid college course: Instructional design notes and recommendations for beginners. MERLOT Journal of Online Learning and Teaching, 1(2). Retrieved from https://jolt.merlot.org/documents/Vol1_No2_hensley.pdf

Kahu, E.R. (2013). Framing student engagement in higher education. Studies in Higher Education, 38(5), $758-773$.

Kuh, G.D., Cruce, T.M., Shoup, R., Kinzie, J., \& Gonyea, R.M. (2008). Unmasking the effects of student engagement on first-year college grades and persistence. The Journal of Higher Education, 79(5), 540-563. 
Kuh, G.D., Kinzie, J., Buckley, J.A., Bridges, B.K., \& Hayek, J.C. (2007). Piecing together the student success puzzle: Research, propositions, and recommendations. ASHE Higher Education Report, 32(5), 1-182. San Fransisco, CA: Jossey-Bass.

Kyei-Blankson, L., \& Godwyll, F. (2010). An examination of learning outcomes in hyflex learning environments. In J. Sanchez \& K. Zhang (Eds.), Proceedings of e-learn 2010--World conference on e-learning in corporate, government, healthcare, and higher education (pp. 532-535).

Orlando, FL: Association for the Advancement of Computing in Education (AACE).

Leach, L. (2016). Exploring discipline differences in student engagement in one institution. Higher Education Research \& Development, 35(4), 772-786.

Lindblom-Ylänne, S., Trigwell, K., Nevgi, A., \& Ashwin, P. (2006). How approaches to teaching are affected by discipline and teaching context. Studies in Higher Education, 31(3), 285-298.

Mandernach, J. (2015). Assessment of student engagement in higher education: A synthesis of literature and assessment tools. International Journal of Learning, Teaching and Educational Research, 12(2), 1-14.

Matthews, K. (2016, September). Students as Partners as the Future of Student Engagement. Student Engagement in Higher Education Journal, 1(1), 1-5.

Montgomery, A., Hayward, D., Dunn, W., Carbonaro, M., \& Amrhein, C. (2015). Blending for student engagement: Lessons learned for MOOCs and beyond. Australasian Journal of Educational Technology, 31(6), 657.

Neumann, R., Parry, S., \& Becher, T. (2002). Teaching and learning in their disciplinary contexts: A conceptual analysis. Studies in Higher Education, 27(4), 405-417.

Pascarella, E.T., Seifert, T.A., \& Blaich, C. (2010). How effective are the NSSE benchmarks in predicting important educational outcomes? Change: The Magazine of Higher Learning, 42(1), 16-22.

Pascarella, E.T., \& Terenzini, P.T. (2005). How college affects students, Volume 2: A third decade of research. San Francisco, CA: Jossey-Bass.

Prohorets, E., \& Plekhanova, M. (2015, February 12). Interaction intensity levels in blended learning environment. Procedia - Social and Behavioral Sciences, 174, 3818-3823.

Pulham, E. (2018). 4 Ideas for Building a Performing Arts Blended-Learning Program. Blended Learning Universe. Retrieved from https://www.blendedlearning.org/4-ideas-for-building-a-performingarts-blended-learning-program/

Renton, B. (2020). Reversals in colleges' fall 2020 reopening plans. Inside Higher Education. Retrieved from https://www.insidehighered.com/quicktakes/2020/08/31/new-database-tracks-reversalscolleges-fall-reopening-plans

Singh, C. (2021). Why flipped classes often flop. Inside Higher Education. Retrieved from https://www.insidehighered.com/advice/2021/01/20/lessons-learned-during-pandemic-abouthow-teach-flipped-classes-most-effectively

Trowler, V., \& Trowler, P. (2010). Student engagement evidence summary. York, UK: Higher Education Academy. 